\title{
Chia Oil Adulteration Detection Based on Spectroscopic Measurements
}

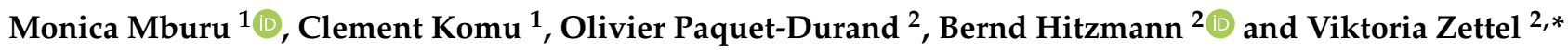 \\ 1 Institute of Food Bioresources Technology, Dedan Kimathi University of Technology, Private Bag, \\ Dedan Kimathi, Nyeri 10143, Kenya; monica.mburu@dkut.ac.ke (M.M.); clementmumo@gmail.com (C.K.) \\ 2 Department of Process Analytics and Cereal Science, Institute of Food Science and Biotechnology, \\ University of Hohenheim, Garbenstr. 23, 70599 Stuttgart, Germany; \\ O.Paquet-Durand@uni-hohenheim.de (O.P.-D.); Bernd.Hitzmann@uni-hohenheim.de (B.H.) \\ * Correspondence: Viktoria.Zettel@uni-hohenheim.de; Tel.: +49-711-459-24460
}

Citation: Mburu, M.; Komu, C.; Paquet-Durand, O.; Hitzmann, B.; Zettel, V. Chia Oil Adulteration Detection Based on Spectroscopic Measurements. Foods 2021, 10, 1798. https://doi.org/10.3390/ foods10081798

Academic Editors: Isabel Mafra and Margit Cichna-Markl

Received: 30 June 2021

Accepted: 3 August 2021

Published: 4 August 2021

Publisher's Note: MDPI stays neutral with regard to jurisdictional claims in published maps and institutional affiliations.

Copyright: (C) 2021 by the authors. Licensee MDPI, Basel, Switzerland. This article is an open access article distributed under the terms and conditions of the Creative Commons Attribution (CC BY) license (https:/ / creativecommons.org/licenses/by/ $4.0 /)$.
Abstract: Chia oil is a valuable source of omega-3-fatty acids and other nutritional components. However, it is expensive to produce and can therefore be easily adulterated with cheaper oils to improve the profit margins. Spectroscopic methods are becoming more and more common in food fraud detection. The aim of this study was to answer following questions: Is it possible to detect chia oil adulteration by spectroscopic analysis of the oils? Is it possible to identify the adulteration oil? Is it possible to determine the amount of adulteration? Two chia oils from local markets were adulterated with three common food oils, including sunflower, rapeseed and corn oil. Subsequently, six chia oils obtained from different sites in Kenya were adulterated with sunflower oil to check the results. Raman, NIR and fluorescence spectroscopy were applied for the analysis. It was possible to detect the amount of adulterated oils by spectroscopic analysis, with a minimum $\mathrm{R}^{2}$ of 0.95 for the used partial least square regression with a maximum $\mathrm{RMSEP}_{\text {range }}$ of $10 \%$. The adulterations of chia oils by rapeseed, sunflower and corn oil were identified by classification with a median true positive rate of $90 \%$. The training accuracies, sensitivity and specificity of the classifications were over $90 \%$. Chia oil B was easier to detect. The adulterated samples were identified with a precision of $97 \%$. All of the classification methods show good results, however SVM were the best. The identification of the adulteration oil was possible; less than $5 \%$ of the adulteration oils were difficult to detect. In summary, spectroscopic analysis of chia oils might be a useful tool to identify adulterations.

Keywords: chia oil; adulteration; spectroscopy; NIR; Raman; fluorescence

\section{Introduction}

Chia, Salvia hispanica L., a member of the Labiatae family, is cultivated in environments ranging from tropical to subtropical conditions and used as a food ingredient. Native from southern Mexico and northern Guatemala, chia has been cultivated on a commercial basis in Australia, Colombia, Argentina, Peru, Ecuador, Bolivia and Paraguay [1]. Research has proved that chia seeds are a good source of oil, protein, dietary fiber, minerals and polyphenolic compounds [2]. Quantitatively, chia seeds contain 91-93 g/100 g dry matter, 26-41 g/100 g carbohydrates, 32-39 g/100 g oil, 22-24 g/100 g protein, 18-30 g/100 g dietary fiber, and 4-6 g/100 g ash, vitamins, antioxidants, minerals contents [3].

Chia oil is known to lower the risks of cardiovascular disease, inflammation, hepatoprotective effect and also to prevent the likelihood of obesity-related disorders [4]. According to research carried out by Gazem et al. [5], investigating in vitro the cancer cytotoxic properties of chia seeds oil and its blends, chia seed oil was found to significantly inhibit anti-lipoxygenase activity, and demonstrated potent and differential anticancer activity. The team concluded that supplementation of a modern diet with chia seeds oil may delay or prevent the incidence of degenerative disorders. Additionally, according to research carried out by Albert et al. [6], it was observed that supplementation of a 
diet with long-chain omega-3 polyunsaturated fatty acids can prevent cardiovascular and inflammatory diseases. Current research has not shown any adverse effects of chia seed consumption, but toxicological data on controlled human trials on the safety and efficacy of chia seed oils are still limited. With the emerging concepts around the combination of chemotherapy and nutritional therapy, there is need to increase data on fatty acid composition in various foods that can be applied in chemotherapeutic subjects. Chia seed oil is becoming an appealing and preferred choice for healthy food and cosmetic applications due to its lower content of saturated fatty acids (palmitic and stearic acids) and adequate concentration of linolenic fatty acids (55-60\%) and linoleic acids (18-20\%) [3]. Both chia seeds and chia seed oil have been safely applied in animal feeds to decrease the cholesterol levels and increase the polyunsaturated fatty acids and in egg and meat products [7]

Extraction of chia oils apply different methods with diverse oil yields including coldpressing followed by centrifugation to remove physical matter, hot-pressing, solvent extraction and supercritical fluid. Chia oil yield and quality in terms of fatty acids composition are affected by several factors including agroecological zones of growth, seed variety, seed storage conditions, pre-treatment method, size reduction practices and the aforementioned extraction procedures [8]. Due to the high value of chia oil, some unscrupulous sellers may adulterate with cheaper oils in order to increase profit. This adulteration will also make the long-chain polyunsaturated fatty acids highly susceptible to lipid hydrolysis and oxidation, thus loosing shelf-life, consumer acceptability, nutritional value, functionality and safety.

Vegetable oils are valuable component of human nutrition. Adulteration of valuable expensive oils with cheaper oils is very common practice. Applying spectroscopic methods provides an opportunity quickly detect these adulterations. There are several works available on olive oil adulteration detection by fluorescence spectroscopy [9-11]. Sikorska et al. [12] were able to distinguish between different edible oils using fluorescence spectroscopy. Near Infrared spectroscopy (NIR) is also well established for food analysis [13]. With data obtained from NIR, UV-Vis and GC, the ComDim chemometrics method was able to distinguish 32 vegetable oil samples by their characteristics and compositions [14]. Rodríguez et al. [15] showed that it is possible to detect adulteration of sesame and chia oils by Fourier transform infrared spectroscopy with prediction errors between $1 \%$ and $5 \%$. Studies on oil adulteration detection with spectroscopic methods have been published by several authors. For example, La Mata et al. [16] used ATR-FTIR spectroscopy and were able to differentiate between blends with olive oil content higher than $50 \%(w / w)$ and those below $50 \%(w / w)$. More examples for the application of FTIR on olive oil adulteration can be found in literature [17-20]. (FT- or M-) IR spectroscopy was also successfully used for sesame oil adulteration [21-25]. Extra virgin olive oil adulteration with hazelnut oil was evaluated using mid-infrared and Raman spectroscopic data [26]. The application of Raman spectroscopy on olive oil adulteration [27] or the combination of Raman and NIR spectroscopy [28] is another way of combining the spectroscopic methods. Adulteration detection by FT-Raman and NIR spectroscopy, combined with data fusion and Soft Independent Modelling of Class Analogy, was performed on a case study to determine the adulteration of hazelnut paste with almonds or chickpeas [29]. Other examples of combinations of NIR and fluorescence were given by $\mathrm{Hu}$ et al. [30], who worked on the fraud detection of Chinese tea oil or by Li et al. [31], who applied these spectroscopic methods to detect adulteration and authenticity of walnut oil.

This study focuses on the adulteration of chia oils with cheaper oils that are available in European and African markets. The more expensive chia oils are currently paid a great deal of attention in African countries, and therefore it is necessary to prevent the valuable oil from adulteration. Adulteration detection is mostly dependent on discriminant analysis, where the spectrum of the test sample is compared to a reference library. The establishment of the reference library usually takes a long time due to the amount of data that has to be covered, e.g., known adulterated samples. Important questions must be answered throughout the process, such as whether a test sample belongs to the native samples or the 
adulterated samples and whether the adulteration can actually be identified. The last but most difficult question is to which amount the test sample has been adulterated.

\section{Materials and Methods}

\subsection{Sample Preparation}

Two different samples of chia oil were purchased, A: Bio Chia Öl (Ölmühle Fandler $\mathrm{GmbH}$, Pöllau, Austria with best before dates of 21 January 2020 and 28 February 2020, origin: Mexico) and B: Chiaöl (Ölmühle Solling GmbH, Boffzen, Germany with best before dates of 7 September 2019 and 26 December 2019, origin: Mexico). For adulteration, common food preparation oils were purchased at the local markets: rapeseed oil (R): Reines Rapsöl, raffiniert (Bökelmann + Co. Ölmühle GmbH \& Co. KG, Hamm, Germany, with best before date 24 April 2020), sunflower oil (S): Reines Sonnenblumenöl, raffiniert (Walter Rau Lebensmittelwerke GmbH, Hilter, Germany, with best before date 17 May 2020), and corn oil (C): Mazola, reines Maiskeimöl (Peter Kölln GmbH \& Co. KG, Elmsholm, Germany, with best before date 27 May 2020). The nutritional values of the oil samples are presented in Table 1.

Table 1. T Nutritional values of the oil samples, for A and B (chia oils) per $100 \mathrm{~g}$, for R, S and C per $100 \mathrm{~mL}$.

\begin{tabular}{|c|c|c|c|c|c|c|c|}
\hline $\begin{array}{c}\text { Sample } \\
\text { Name }\end{array}$ & Energy [kJ] & $\begin{array}{c}\text { Energy } \\
\text { [kcal] }\end{array}$ & Fat $[g]$ & $\begin{array}{c}\text { Saturated } \\
\text { Fatty Acids } \\
{[\mathrm{g}]}\end{array}$ & $\begin{array}{c}\text { Single Unsat. } \\
\text { Fatty Acids } \\
\text { [g] }\end{array}$ & $\begin{array}{l}\text { Multiple } \\
\text { Unsat. Fatty } \\
\text { Acids [g] }\end{array}$ & $\begin{array}{l}\text { Vitamin E } \\
{[\mathrm{mg}]}\end{array}$ \\
\hline A (chia oil) & 3700 & 900 & 100 & 10.1 & 7.8 & 82.1 & - \\
\hline B (chia oil) & 3700 & 900 & 100 & 10.6 & 7.2 & 82.2 & - \\
\hline $\mathrm{R}$ (rapeseed) & 3404 & 828 & 92 & 6.5 & 60 & 25.5 & 46 \\
\hline S (sunflower) & 3404 & 828 & 92 & 10 & 28 & 54 & 30 \\
\hline$C(\operatorname{cor} n)$ & 3404 & 828 & 92 & 13 & 28 & 51 & 37 \\
\hline
\end{tabular}

In Table 2, the sample preparation and its labelling for the Mexican chia oils is presented. Every sample was prepared three times, and 114 samples were collected. The sample volume remained constant at $3.5 \mathrm{~mL}$.

Table 2. Sample preparation and labelling for the spectroscopic analysis. A and B are the two Mexican chia oils, $\mathrm{S}$ is sunflower oil, $\mathrm{R}$ is rapeseed oil and $\mathrm{C}$ is corn oil. All values are mass percentages.

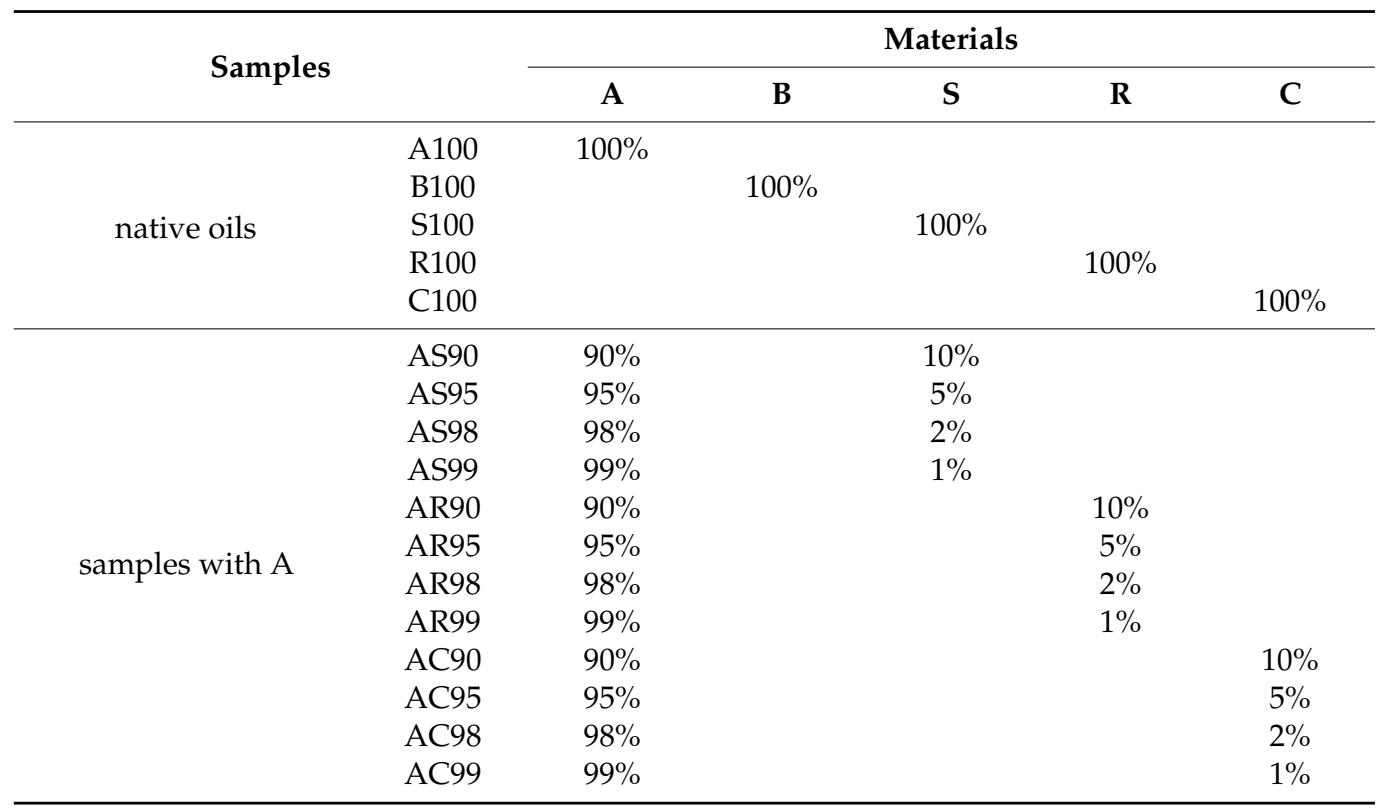


Table 2. Cont.

\begin{tabular}{|c|c|c|c|c|c|c|}
\hline \multirow{2}{*}{ Samples } & & \multicolumn{5}{|c|}{ Materials } \\
\hline & & A & B & $S$ & $\mathbf{R}$ & $\mathrm{C}$ \\
\hline \multirow{12}{*}{ samples with B } & BS90 & & $90 \%$ & $10 \%$ & & \\
\hline & BS95 & & $95 \%$ & $5 \%$ & & \\
\hline & BS98 & & $98 \%$ & $2 \%$ & & \\
\hline & BS99 & & $99 \%$ & $1 \%$ & & \\
\hline & BR90 & & $90 \%$ & & $10 \%$ & \\
\hline & BR95 & & $95 \%$ & & $5 \%$ & \\
\hline & BR98 & & $98 \%$ & & $2 \%$ & \\
\hline & BR99 & & $99 \%$ & & $1 \%$ & \\
\hline & ВС 90 & & $90 \%$ & & & $10 \%$ \\
\hline & BC95 & & $95 \%$ & & & $5 \%$ \\
\hline & ВС 98 & & $98 \%$ & & & $2 \%$ \\
\hline & ВС99 & & $99 \%$ & & & $1 \%$ \\
\hline \multirow{9}{*}{$\begin{array}{l}\text { additional } \\
\text { combinations }\end{array}$} & RS50 & & & $50 \%$ & $50 \%$ & \\
\hline & RC50 & & & & $50 \%$ & $50 \%$ \\
\hline & SC50 & & & $50 \%$ & & $50 \%$ \\
\hline & AS50 & $50 \%$ & & $50 \%$ & & \\
\hline & AR50 & $50 \%$ & & & $50 \%$ & \\
\hline & AC50 & $50 \%$ & & & & $50 \%$ \\
\hline & BS50 & & $50 \%$ & $50 \%$ & & \\
\hline & BR50 & & $50 \%$ & & $50 \%$ & \\
\hline & BC50 & & $50 \%$ & & & $50 \%$ \\
\hline
\end{tabular}

For Kenyan chia oil samples, named oil U, V, W, X, Y, Z (from chia seeds obtained from different growth sites in Kenya) a smaller sample volume $(2 \mathrm{~mL})$ was chosen because of the small number of samples available. Its samples were prepared, according to Table 3 , two times with exceptions (indicated with ${ }^{*}$ ), which were prepared once. Therefore, 28 different samples were obtained from Kenyan chia oil. All samples were directly prepared in a quartz glass cuvette and mixed by gently shaking. Then the cuvettes were placed in the respective spectrometer.

Table 3. Sample preparation for the additional Kenyan chia oil samples (U-Z) that were adulterated with sunflower oil (S). Samples indicated with * were prepared only once, the others were prepared two times.

\begin{tabular}{|c|c|c|c|c|c|c|c|}
\hline \multirow[t]{2}{*}{ Samples } & \multicolumn{7}{|c|}{ Materials } \\
\hline & $\mathbf{U}$ & $\mathbf{V}$ & $\mathbf{W}$ & $X$ & $Y$ & $\mathbf{Z}$ & $S$ \\
\hline U100 * & $100 \%$ & & & & & & \\
\hline V100 & & $100 \%$ & & & & & \\
\hline W100 & & & $100 \%$ & & & & \\
\hline $\mathrm{X} 100$ * & & & & $100 \%$ & & & \\
\hline Y100 & & & & & $100 \%$ & & \\
\hline Z100 & & & & & & $100 \%$ & \\
\hline US90 * & $90 \%$ & & & & & & $10 \%$ \\
\hline US50 * & $50 \%$ & & & & & & $50 \%$ \\
\hline VS90 & & $90 \%$ & & & & & $10 \%$ \\
\hline VS50 & & $50 \%$ & & & & & $50 \%$ \\
\hline WS50 * & & & $50 \%$ & & & & $50 \%$ \\
\hline XS90* & & & & $90 \%$ & & & $10 \%$ \\
\hline XS50 & & & & $50 \%$ & & & $50 \%$ \\
\hline YS90 & & & & & $90 \%$ & & $10 \%$ \\
\hline YS50 & & & & & $50 \%$ & & $50 \%$ \\
\hline ZS90 & & & & & & $90 \%$ & $10 \%$ \\
\hline ZS50 & & & & & & $50 \%$ & $50 \%$ \\
\hline
\end{tabular}

* All together 142 samples are used for spectroscopic measurement. 


\subsection{Spectroscopic Measurements}

Three spectrometers were used to obtain near infrared (NIR), Raman and fluorescence spectra of the oil samples. NIR spectroscopy measurements were performed in the MultiPurpose NIR Analyzer (Bruker Optik GmbH, Ettlingen, Germany), varying wavelengths from $800 \mathrm{~nm}$ to $2800 \mathrm{~nm}$, in absorbance, with a resolution of $15 \mathrm{~nm}$ and 8 scans per measurement.

Raman spectroscopy was performed with a FT-Raman785 spectrometer (Inno-spec GmbH, Model 11-0130005-119, Nürnberg, Germany), equipped with a $784.98 \mathrm{~nm}$ Laser applying a measurement range from $350 \mathrm{~cm}^{-1}$ to $3200 \mathrm{~cm}^{-1}$. The integration time was $1 \mathrm{~s}$ and 3 scans were performed for each measurement. The background was measured with an empty cuvette.

3D-fluorescence spectra were obtained with FluoroMax4 Spectrofluorometer (HORIBA JOBIN YVON Technology, Edison, NY, USA). Spectra were analysed in a range between $300 \mathrm{~nm}$ and $550 \mathrm{~nm}$ of excitation and $350 \mathrm{~nm}$ and $700 \mathrm{~nm}$ emission with $10 \mathrm{~nm}$ distance steps and a slit width of $1 \mathrm{~nm}$. In total, the resulting spectra contained 936 measured intensities of wavenumber and wavelength combinations.

Every prepared sample was measured 5 times. In total, 142 samples were measured. Every single spectrum was used for the analysis, in total 710 spectra were obtained for each spectroscopic method. The resulting combined spectra contained 2751 points.

\subsection{Spectra Evaluation: Preprocessing}

The evaluation of the spectra was performed with Matlab R2020a (version 9.8). The spectra were pre-processed with different methods to extract the desired information. A baseline correction and a standard normal variate (SNV) transformation was applied to Raman and NIR spectra. For the baseline correction, the following Matlab code, presented in Equation (1), was applied in a loop using the intensity values of all wavenumbers $k$ in a spectrum.

$$
I_{B C}(k)=I(k)-\operatorname{cumsum}[\operatorname{smooth}(\operatorname{diff}\{I(k)\}, 20)]
$$

$I_{B C}(k)$ is the baseline corrected intensity value, $I(k)$ the raw intensity, cumsum, smooth and diff are Matlab functions. To harmonize the spectra further, a standard normal variate transformation, presented in Equation (2), was applied as follows

$$
I_{S N V}(k)=\frac{I_{B C}(k)-\bar{I}_{B C}}{S D_{B C}}
$$

$I_{S N V}(k)$ is the transformed intensity, $\bar{I}_{B C}$ and $S D_{B C}$ are the mean value and standard deviation of the base line corrected spectrum. For the fluorescence spectra, no pre-processing was applied. The spectra were then evaluated separately for each spectrometer typ. For further evaluations NIR, fluorescence and Raman spectra were combined. The intensities of the fluorescence spectra were therefore scaled down with a SNV transformation, subsequently the NIR and Raman spectra were appended to the fluorescence spectra to produce combined spectra.

\subsection{Spectra Evaluation: Classification}

The classification was performed by using the Classification Learner App, which is implemented in Matlab. The following classification algorithms were tested: decision tree (DT), linear discriminant analysis (LD), k nearest neighbour classification (KNN), support vector machine linear (SVMl) and cubic (SVMc). The classification was performed with 5 classes: 1 . A, 2. Adult A, 3. B, 4. Adult B, 5. Adult. The classification was performed to check if $A$ and $B$ samples of the native oils could be distinguished and if an adulteration was present. For Adult A and Adult B, the 12 samples with A and B were complemented by 3 corresponding samples of the additional combinations presented in Table 2 . Therefore, 225 spectra were in both classes. To obtain equal number of spectra in every class some simulation spectra were calculated, so that every class was enlarged to 225 spectra. 
The number of pure oil samples of class A and B resulted just in 15 spectra each, therefore new spectra were simulated out of them. First, the means $\mathrm{m}$ and the standard deviations SD of intensity values for all wavenumbers (Raman and NIR) or wavelength combination (fluorescence) for both classes were individually calculated. 150 spectra for each pure oil sample were simulated by adding to each value in the mean (75) or the original (75) spectrum the corresponding standard deviation times a standard normal distributed random number, which has a cero mean and a standard deviation of one, as shown in Equation (3).

$$
\widetilde{I}(k)=I(k)+S D(k) \times \operatorname{ran}(k)
$$

Here $\widetilde{I}(k)$ is the simulated intensity value, $\mathrm{k}$ is either the wavenumber (for Raman and NIR) or an index for the wavelength combinations (fluorescence), $I(k)$ is the corresponding mean or original value and $S D(k)$ the corresponding standard deviation, $r a n(k)$ is a standard normal distributed random number, which is calculated for each $\mathrm{k}$. To complete the class A and B data sets to 225 spectra, the original spectra were used five times.

For the "Adult" class, the $100 \%$ pure samples of S, R and C as well as the corresponding additional combinations (RS50, RC50, SC50), which were 90 spectra together, were complemented by 90 simulated spectra obtained in the same manner as discussed before (Equation (3)) from the samples S, R and C. To complete the data set of class "Adult", 45 replication spectra from $S, R$ and $C$ samples were added. In total 1125 spectra were obtained, where each class consisted of 225 spectra.

The quality of the classification is assessed with the amount of correct detected samples, which is calculated as \% of samples in the validation dataset and is presented as True Positive Rate (TPR). The sensitivity (Equation (4)), specificity (Equation (5)), accuracy (Equation (6)) and precision (Equation (7)) are calculated with the values of true positive $(\mathrm{TP})$, true negative (TN), false negative (FN) and false positive (FP) identified samples [32].

$$
\begin{gathered}
\text { Sensitivity }(\%)=\mathrm{TP} /(\mathrm{TP}+\mathrm{FN}) \cdot 100 \%, \\
\text { Specificity }(\%)=\mathrm{TN} /(\mathrm{TN}+\mathrm{FP}) \cdot 100 \%, \\
\text { Accuracy }(\%)=(\mathrm{TP}+\mathrm{TN}) /(\mathrm{TP}+\mathrm{TN}+\mathrm{FP}+\mathrm{FN}) \cdot 100 \%, \\
\text { Precision }(\%)=\mathrm{TP} /(\mathrm{TP}+\mathrm{FP}) 100 \%,
\end{gathered}
$$

\subsection{Spectra Evaluation: Partial Least Squares Regression}

Partial Least Squares Regression (PLSR) models are calculated for each oil to predict the adulteration levels. For the Mexican chia oil samples, A and B, 1 up to 32 principal components (3-10 for Kenyan samples, depending on the number of measured samples) are tested for the PLSR model. A leave-one-out-cross-validation (CV) is performed for each dataset. The coefficient of determination $\mathrm{R}^{2}$ and the root mean square error of prediction RMSEP $_{\text {range }}$ are calculated.

The detection limit dl for the PLSR was calculated from the blank sample (100\% pure chia oil) with Equation (8), where $\mathrm{m}$ is the mean and SD is the standard deviation.

$$
\mathrm{dl}=\mathrm{m}_{100 \% \text { chia oil }}+3 \mathrm{SD}_{100 \% \text { chia oil }}
$$

\section{Results and Discussion}

The native oils could easily be distinguished by their fluorescence spectra (Figure 1). All of the oils differ in intensities and slight intensity regions. It was assumed that the best results would be obtained through fluorescence spectra evaluation. The visible peaks can be assigned to pigments of groups belonging to NADH, tocopherols, riboflavin (emission $524 \mathrm{~nm}$ ), oxidation products of oil ingredients e.g., vitamin $\mathrm{E}$ derivates at $525 \mathrm{~nm}$ emission and chlorophyll at excitation $405 \mathrm{~nm}$ and emission $670 \mathrm{~nm}$ [10-12,33-35]. However, the oils were not prepared in a special way or measured in a solvent; therefore, the ranges might have shifted and/or the intensities might be lower. Since we work with raw materials that 
are subject to natural variations, it is definitely possible that the spectra of two oils are not one in the same. The fluorescence spectra of the chia oils show the same intensity regions. Overall, all of the oils examined show higher intensities in the regions of carotenoids, tocopherols, polyphenols and chlorophylls. Lower intensities in the regions of $350 \mathrm{~nm}$ excitation and $400 \mathrm{~nm}$ to $450 \mathrm{~nm}$ emission indicate the presence of oxidation products formed during oil ageing. Observing Figure 1 in-depth, it is obvious that the intensities of the oils used for adulteration (sunflower, rape seed and corn) have higher intensities in the respective regions.
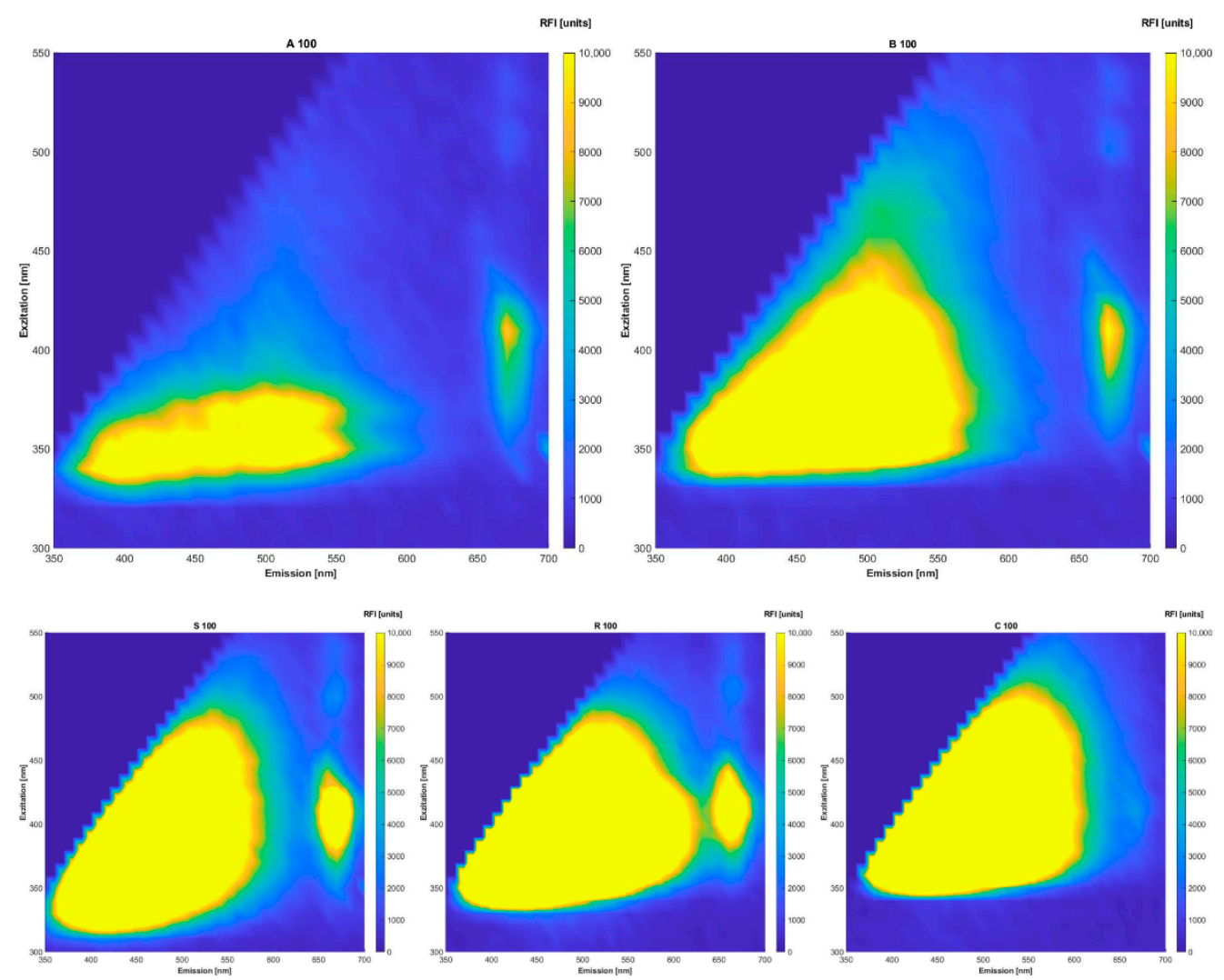

Figure 1. Fluorescence spectra of native oils, A: chia, B: chia, S: sunflower, R: rape seed, C: corn.

For NIR and Raman spectra, the native oil spectra are presented in Figures 2 and 3. The left side shows the raw spectra, whereas the right side shows the pre-processed spectra. For the combined evaluation, the fluorescence spectra were also pre-processed by SNV, and therefore the intensities are comparable. For NIR spectra, no big differences between the samples are obvious, but in the Raman spectra different intensities for the samples are visible. In Figure 4, the combined spectra of all native oils are presented. The spectra of A and $\mathrm{B}$ show differences compared to the other oils. 

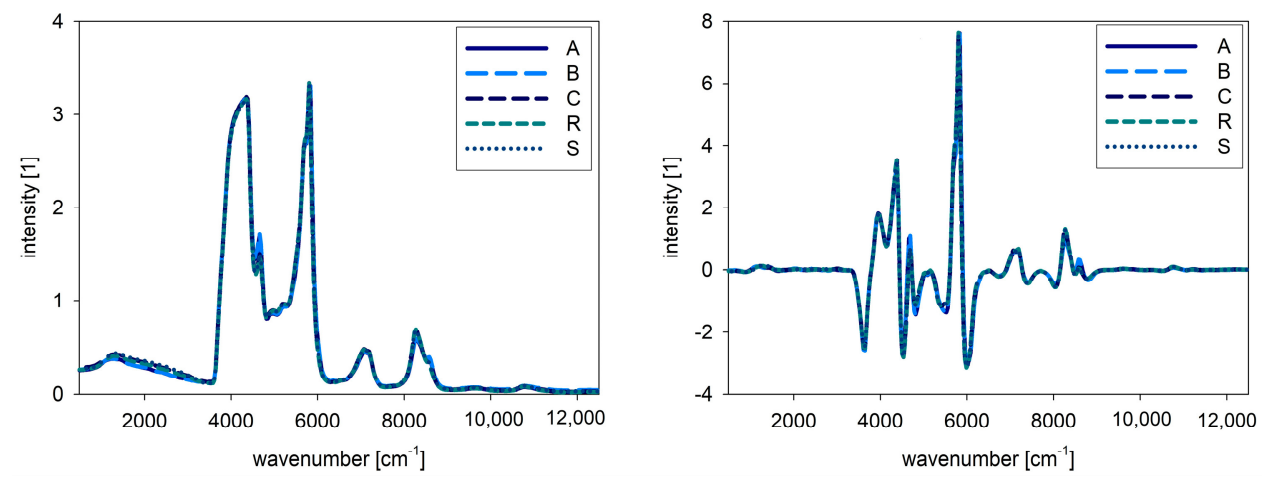

Figure 2. NIR spectra of native oils, A: chia, B: chia, R: rape seed, S: sunflower, C: corn, raw spectra (left), pre-processed spectra (right).
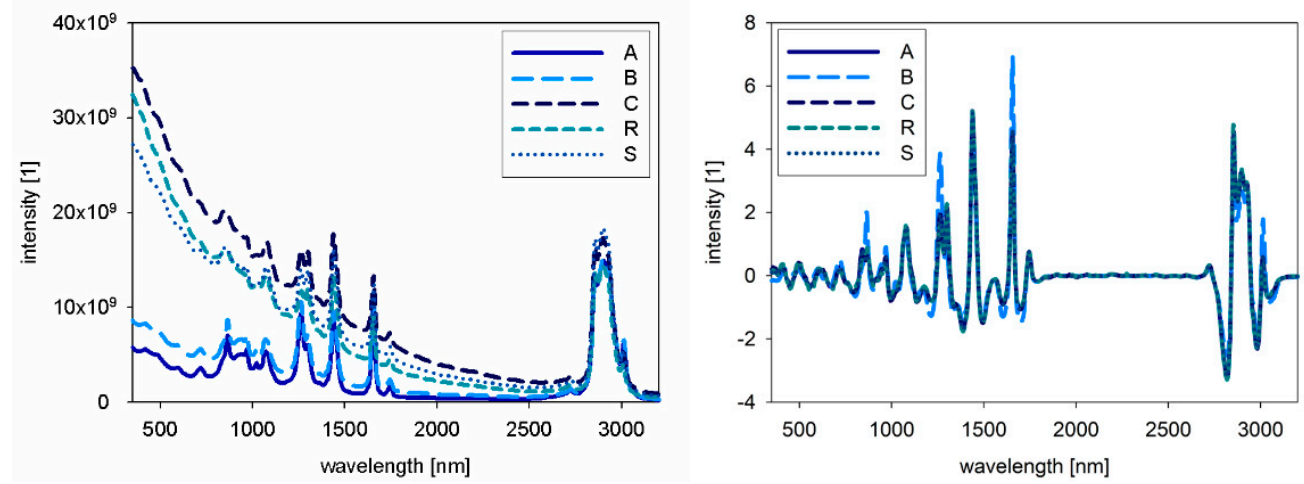

Figure 3. Raman spectra of native oils, A: chia, B: chia, R: rape seed, S: sunflower, C: corn, raw spectra (left), pre-processed spectra (right).

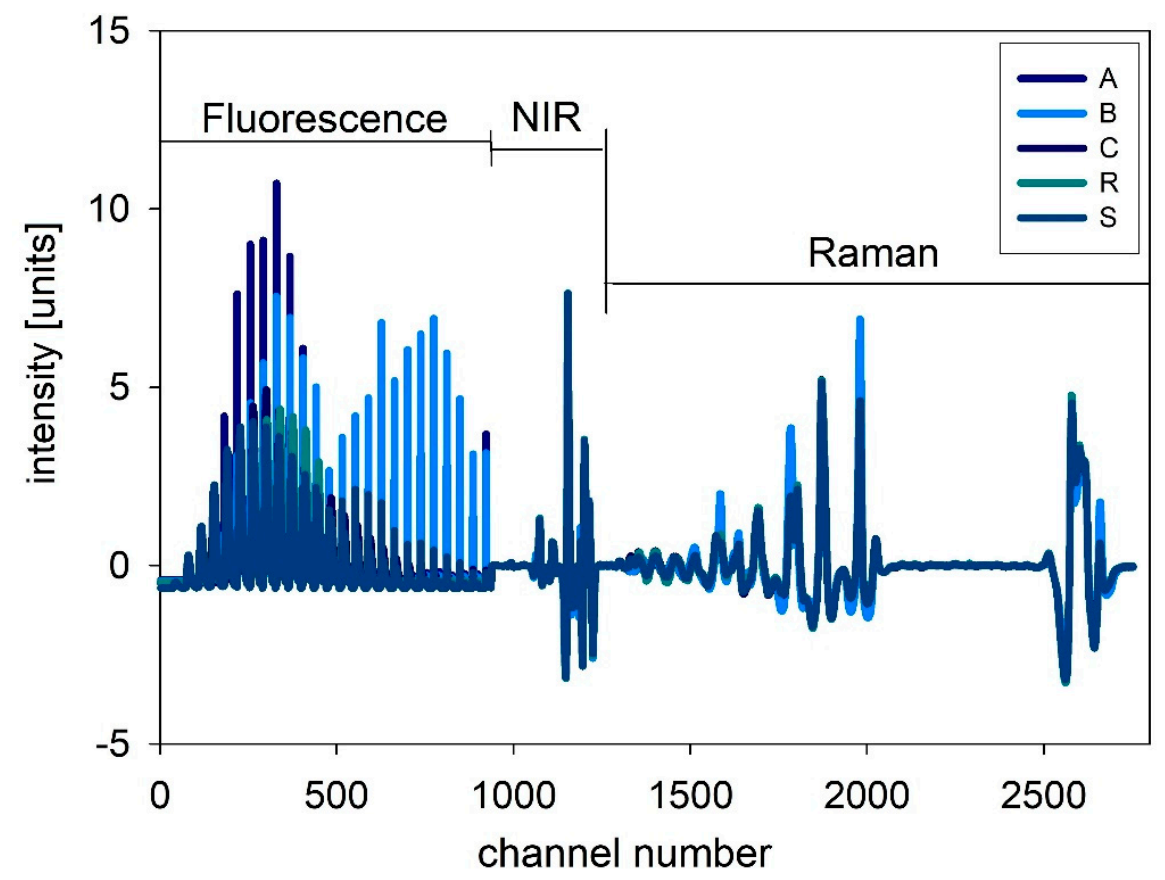

Figure 4. Combination of all spectra for evaluation. 
Mean values and standard deviations for the ten classification runs can be found in Tables 4 and 5 . The best results for the classification were obtained with a TPR of $99.7 \%$ for the classification with SVMc and the combination of all of the spectra together (Table 5). The combination of fluorescence and NIR spectra were classified with a TPR of $99.5 \%$ with SVMc, and SVMc is also the best classification method for all single spectra. The medians for the TPR, sensitivity, specificity and accuracy of the classification are presented in Figure 5. The median TPR is over $90 \%$ for most of the calculations. As usual, the training accuracies are, with exceptions, all over $90 \%$, higher than the validation accuracies which were between $71 \%$ and $79.9 \%$. The sensitivity as well as the specificity were over $90 \%$ for all of the samples. However, B was better detected. The precision was around $100 \%$ for pure B samples whereas for A, the precision was poor with $54.2 \pm 3 \%$ for the Raman spectra classification by KNN. The precision for adulterated samples was over $90 \%$. It is obvious that $\mathrm{KNN}$ results in the poorest classification results for $\mathrm{A}$ and $\mathrm{B}$ as well as for all measured spectra and their combinations. Adulterations for A were incorrectly classified.

Table 4. Results of the classification of samples with single spectra; Means and standard deviations of 10 classification runs.

\begin{tabular}{|c|c|c|c|c|c|}
\hline Fluorescence & 1 Tree & $2 \mathrm{LD}$ & $3 \mathrm{KNN}$ & 4 SVMl & 5 SVMc \\
\hline TPR & $94.9 \pm 1.6$ & $94.9 \pm 1.6$ & $93.2 \pm 1.4$ & $92.8 \pm 1$ & $98.1 \pm 2$ \\
\hline Accuracy training & $95 \pm 0.7$ & $97.1 \pm 0.5$ & $92.9 \pm 0.4$ & $92.9 \pm 0.4$ & $97.5 \pm 0.7$ \\
\hline Accuracy validation & $78 \pm 0.6$ & $78 \pm 0.6$ & $77.3 \pm 0.6$ & $77.1 \pm 0.4$ & $79.3 \pm 0.8$ \\
\hline Sensitivity A & $94.6 \pm 2.9$ & $94.6 \pm 2.9$ & $100 \pm 0$ & $100 \pm 0$ & $100 \pm 0$ \\
\hline Sensitivity B & $100 \pm 0$ & $100 \pm 0$ & $100 \pm 0$ & $100 \pm 0$ & $100 \pm 0$ \\
\hline Specificity A & $97.9 \pm 1.1$ & $97.9 \pm 1.1$ & $93.3 \pm 1.8$ & $99.6 \pm 0.5$ & $99.8 \pm 0.3$ \\
\hline Specificity B & $100 \pm 0$ & $100 \pm 0$ & $100 \pm 0$ & $100 \pm 0$ & $100 \pm 0$ \\
\hline Precision A & $91.2 \pm 4.9$ & $91.2 \pm 4.9$ & $78.1 \pm 6.3$ & $98.1 \pm 2.7$ & $99.3 \pm 1.2$ \\
\hline Precision B & $100 \pm 0$ & $100 \pm 0$ & $100 \pm 0$ & $100 \pm 0$ & $100 \pm 0$ \\
\hline NIR & 6 tree & $7 \mathrm{LD}$ & $8 \mathrm{KNN}$ & 9 SVM1 & 10 SVMc \\
\hline TPR & $95.8 \pm 2.2$ & $95.8 \pm 2.2$ & $90.2 \pm 1.8$ & $97.2 \pm 1.3$ & $98.4 \pm 0.7$ \\
\hline Accuracy training & $95.3 \pm 0.5$ & $95.5 \pm 0.8$ & $90.7 \pm 0.3$ & $97.6 \pm 0.4$ & $98.5 \pm 0.3$ \\
\hline Accuracy validation & $78.3 \pm 0.9$ & $78.3 \pm 0.9$ & $76.1 \pm 0.7$ & $78.9 \pm 0.5$ & $79.4 \pm 0.3$ \\
\hline Sensitivity A & $95.5 \pm 2.9$ & $95.5 \pm 2.9$ & $100 \pm 0$ & $100 \pm 0$ & $100 \pm 0$ \\
\hline Sensitivity B & $99.5 \pm 1.1$ & $99.5 \pm 1.1$ & $100 \pm 0$ & $100 \pm 0$ & $100 \pm 0$ \\
\hline Specificity A & $98.7 \pm 0.9$ & $98.7 \pm 0.9$ & $90.2 \pm 1.7$ & $98.6 \pm 0.9$ & $99 \pm 0.6$ \\
\hline Specificity B & $100 \pm 0$ & $100 \pm 0$ & $100 \pm 0$ & $100 \pm 0$ & $100 \pm 0$ \\
\hline Precision A & $94.7 \pm 3.1$ & $94.7 \pm 3.1$ & $71 \pm 5.4$ & $94.4 \pm 3.2$ & $96.1 \pm 2.2$ \\
\hline Precision B & $100 \pm 0$ & $100 \pm 0$ & $100 \pm 0$ & $100 \pm 0$ & $100 \pm 0$ \\
\hline Raman & 11 tree & 12 LD & $13 \mathrm{KNN}$ & 14 SVM1 & 15 SVMc \\
\hline TPR & $92.2 \pm 2.5$ & $92.2 \pm 2.5$ & $79.6 \pm 2.6$ & $96.4 \pm 0.7$ & $98 \pm 0.4$ \\
\hline Accuracy training & $92.3 \pm 1.2$ & $97 \pm 0.3$ & $79 \pm 0.6$ & $97.3 \pm 0.3$ & $98.4 \pm 0.2$ \\
\hline Accuracy validation & $76.9 \pm 1$ & $76.9 \pm 1$ & $71.8 \pm 1$ & $78.6 \pm 0.3$ & $79.2 \pm 0.2$ \\
\hline Sensitivity A & $96 \pm 3.6$ & $96 \pm 3.6$ & $100 \pm 0$ & $100 \pm 0$ & $100 \pm 0$ \\
\hline Sensitivity B & $98.5 \pm 2$ & $98.5 \pm 2$ & $100 \pm 0$ & $100 \pm 0$ & $100 \pm 0$ \\
\hline Specificity A & $96.5 \pm 2.1$ & $96.5 \pm 2.1$ & $81.5 \pm 2.9$ & $99.5 \pm 0.5$ & $99.7 \pm 0.3$ \\
\hline Specificity B & $99.9 \pm 0.2$ & $99.9 \pm 0.2$ & $100 \pm 0$ & $100 \pm 0$ & $100 \pm 0$ \\
\hline Precision A & $87.1 \pm 7.1$ & $87.1 \pm 7.1$ & $56.7 \pm 5.8$ & $97.9 \pm 2.4$ & $98.8 \pm 1.3$ \\
\hline Precision B & $99.8 \pm 0.8$ & $99.8 \pm 0.8$ & $100 \pm 0$ & $100 \pm 0$ & $100 \pm 0$ \\
\hline
\end{tabular}


Table 5. Results of the classification of samples with combinations of spectra; means and standard deviations of 10 classification runs.

\begin{tabular}{|c|c|c|c|c|c|}
\hline Fluo + NIR + Raman & 16 Tree & 17 LD & $18 \mathrm{KNN}$ & 19 SVM1 & 20 SVMc \\
\hline TPR & $98.1 \pm 0.6$ & $98.1 \pm 0.6$ & $91.2 \pm 2$ & $99.2 \pm 0.4$ & $99.7 \pm 0.3$ \\
\hline Accuracy training & $97.5 \pm 0.6$ & $99.4 \pm 0.1$ & $90.7 \pm 0.3$ & $99.2 \pm 0.2$ & $99.6 \pm 0.2$ \\
\hline Accuracy validation & $79.2 \pm 0.3$ & $79.2 \pm 0.3$ & $76.5 \pm 0.8$ & $79.7 \pm 0.2$ & $79.9 \pm 0.1$ \\
\hline Sensitivity A & $98.3 \pm 2$ & $98.3 \pm 2$ & $100 \pm 0$ & $100 \pm 0$ & $100 \pm 0$ \\
\hline Sensitivity B & $99.7 \pm 0.9$ & $99.7 \pm 0.9$ & $100 \pm 0$ & $100 \pm 0$ & $100 \pm 0$ \\
\hline Specificity A & $98.8 \pm 0.5$ & $98.8 \pm 0.5$ & $89.7 \pm 1.9$ & $99.5 \pm 0.6$ & $99.8 \pm 0.3$ \\
\hline Specificity B & $99.9 \pm 0.4$ & $99.9 \pm 0.4$ & $100 \pm 0$ & $100 \pm 0$ & $100 \pm 0$ \\
\hline Precision A & $95.2 \pm 2.2$ & $95.2 \pm 2.2$ & $70 \pm 5.4$ & $97.9 \pm 2.9$ & $99.3 \pm 1.2$ \\
\hline Precision B & $99.7 \pm 1$ & $99.7 \pm 1$ & $100 \pm 0$ & $100 \pm 0$ & $100 \pm 0$ \\
\hline Fluo + NIR & 21 tree & 22 LD & $23 \mathrm{KNN}$ & 24 SVM1 & 25 SVMc \\
\hline TPR & $97.1 \pm 1$ & $97.1 \pm 1$ & $94.5 \pm 1.1$ & $98.4 \pm 1.1$ & $99.5 \pm 0.5$ \\
\hline Accuracy training & $97.1 \pm 0.7$ & $99.5 \pm 0.2$ & $94.5 \pm 0.3$ & $98 \pm 0.3$ & $99.5 \pm 0.1$ \\
\hline Accuracy validation & $78.8 \pm 0.4$ & $78.8 \pm 0.4$ & $77.8 \pm 0.4$ & $79.3 \pm 0.4$ & $79.8 \pm 0.2$ \\
\hline Sensitivity A & $94.6 \pm 3.8$ & $94.6 \pm 3.8$ & $100 \pm 0$ & $100 \pm 0$ & $100 \pm 0$ \\
\hline Sensitivity B & $99.7 \pm 0.9$ & $99.7 \pm 0.9$ & $100 \pm 0$ & $100 \pm 0$ & $100 \pm 0$ \\
\hline Specificity A & $99 \pm 0.7$ & $99 \pm 0.7$ & $93.6 \pm 1.4$ & $99 \pm 0.8$ & $99.3 \pm 0.5$ \\
\hline Specificity B & $100 \pm 0$ & $100 \pm 0$ & $100 \pm 0$ & $100 \pm 0$ & $100 \pm 0$ \\
\hline Precision A & $95.7 \pm 3.2$ & $95.7 \pm 3.2$ & $78.8 \pm 5.1$ & $95.7 \pm 3.5$ & $97.2 \pm 2.6$ \\
\hline Precision B & $100 \pm 0$ & $100 \pm 0$ & $100 \pm 0$ & $100 \pm 0$ & $100 \pm 0$ \\
\hline
\end{tabular}

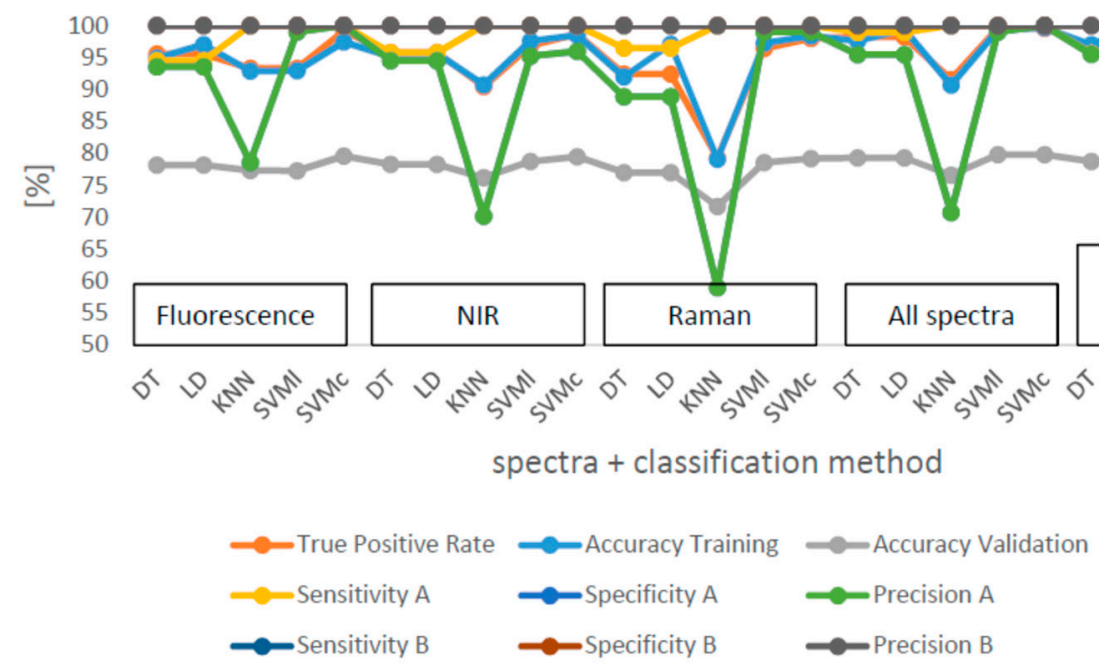

Figure 5. Median of 10 runs for TPR, accuracy of training and validation, sensitivity, specificity and precision of the classification for all evaluated spectra and combined variations as well as different classification methods; DT: decision tree, LD: linear discriminant analysis, KNN: nearest neighbour classification, SVMl and SVMc: support vector machines linear and cubic.

For Raman spectra evaluation, KNN resulted in a false classification of $64.3 \%$ for Adult A and a false classification of $33.3 \%$ for Adult B for one out of ten classifications (Figure 6). The same classification method leads to the combined evaluation of fluorescence and NIR spectra (Figure 7) to only a false classification of $35.7 \%$ of Adult A, which indicated that somehow the adulteration samples of chia oil A are more difficult to detect in general. The best results were obtained for the combined evaluation of fluorescence and NIR spectra, the confusion matrix of one classification run is presented in Figure 8. The wrong classifications are more or less equally distributed over all samples and remain below $10 \%$. A successful classification is hence possible for 5 classes. KNN does not seem to be sufficient for these classification processes. 
The presented method was capable of identifying most of the samples in the validation trial. It is a fast method which is easy to use after a calibration. The quantification of other compounds in the oil might also be possible with this method but this was not the focus of this study. The time-saving after the calibration of a spectroscopic method is around 2 to 3 times faster [36]. This underlines the necessity of the validation, which was successfully performed in this study.

The best results of the PLSR are presented in Table 6. The coefficients of determination are above 0.95 for all samples. Given the fact that the extreme points (the native oils) could be distinguished quite easily, this is not surprising.
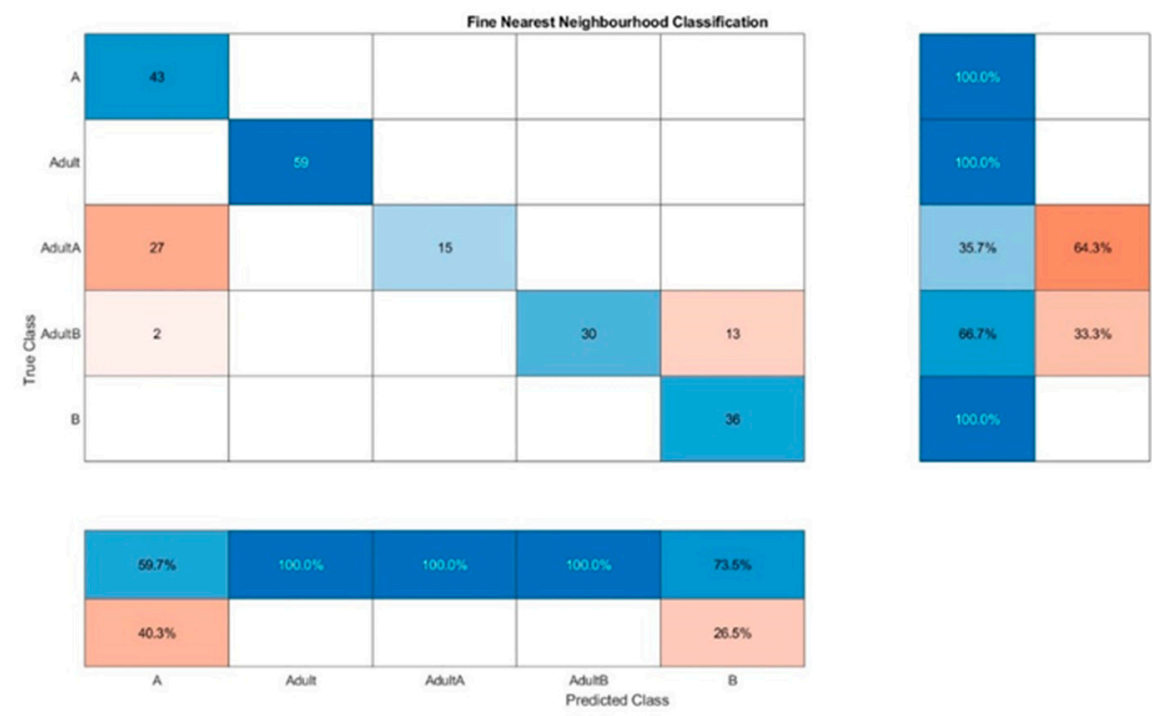

Figure 6. Confusion matrix for the oil classification by KNN out of the Raman spectra.
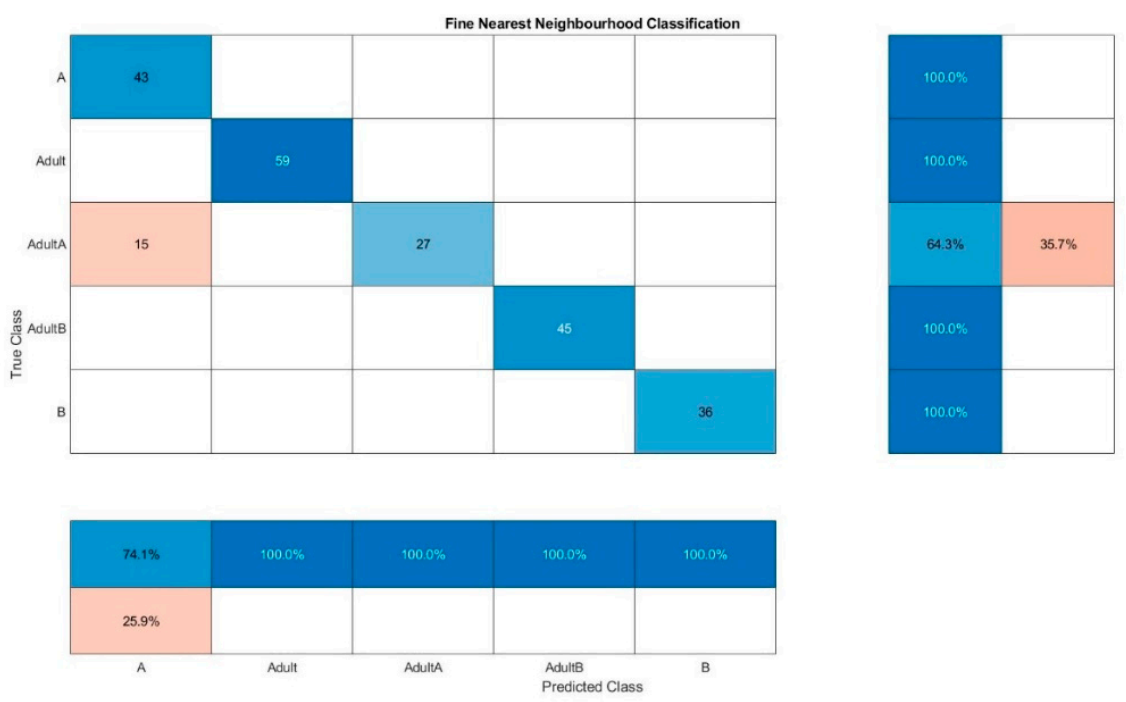

Figure 7. Confusion matrix for the oil classification by KNN out of the combined evaluation of the fluorescence and NIR spectra. 

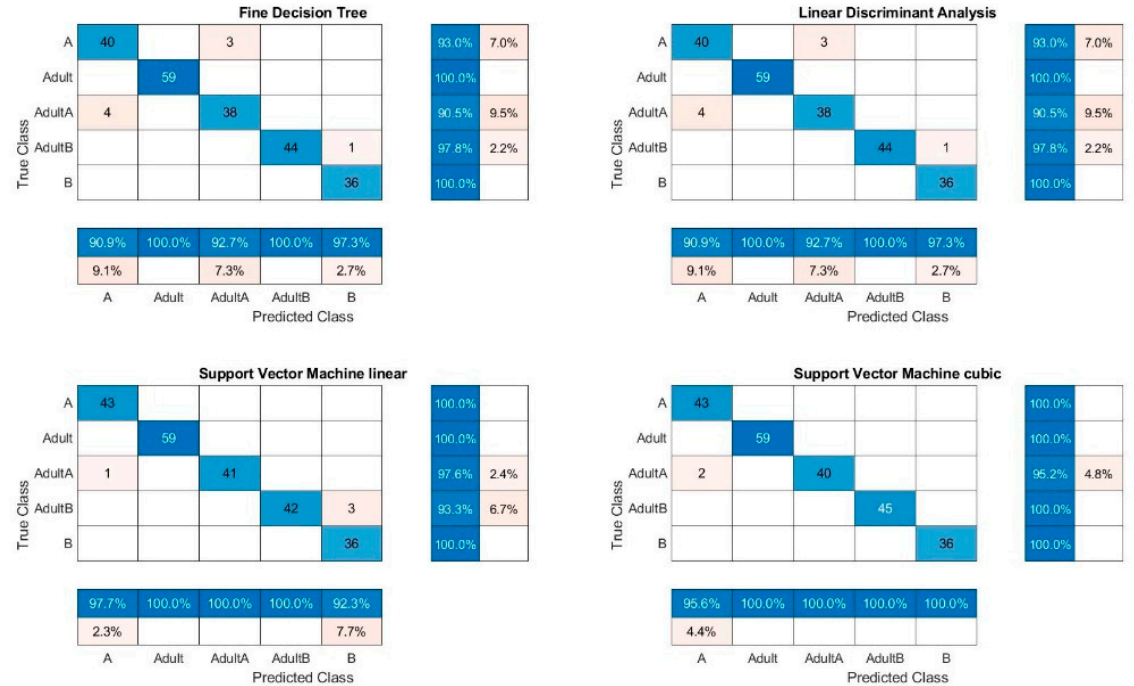

Figure 8. Confusion matrix for the oil classification by DT, LDA, SVMl \& SVMc out of the combined evaluation of the fluorescence and NIR spectra.

Table 6. Results of the best PLSR predictions for the single oils A and B with single evaluations of the adulteration oils R, S, and $\mathrm{C}$ and the combination of all adulterations with the samples all separately for all methods and the combination of all methods.

\begin{tabular}{|c|c|c|c|c|}
\hline & Oil & $\mathbf{R}^{2}$ & RMSEPrange & Detection Limit [\%] \\
\hline \multirow{8}{*}{$\begin{array}{l}\text { Fluorescence with } \\
\text { Preprocessing }\end{array}$} & $\mathrm{AC}$ & 0.994 & 2.7 & 8.3 \\
\hline & AR & 0.988 & 3.8 & 8.6 \\
\hline & AS & 0.993 & 2.9 & 7.2 \\
\hline & A all & 0.991 & 3.4 & 8.7 \\
\hline & $\mathrm{BC}$ & 0.992 & 3.2 & 6.1 \\
\hline & BR & 0.992 & 3.1 & 17.9 \\
\hline & BS & 0.983 & 4.7 & 18.6 \\
\hline & $\mathrm{B}$ all & 0.990 & 3.6 & 15.4 \\
\hline \multirow{8}{*}{$\begin{array}{l}\text { Fluorescence without } \\
\text { Preprocessing }\end{array}$} & $\mathrm{AC}$ & 0.994 & 2.7 & 10.0 \\
\hline & AR & 0.988 & 3.9 & 9.4 \\
\hline & AS & 0.993 & 2.9 & 7.4 \\
\hline & A all & 0.991 & 3.4 & 7.8 \\
\hline & $\mathrm{BC}$ & 0.991 & 3.3 & 7.6 \\
\hline & $\mathrm{BR}$ & 0.992 & 3.1 & 17.9 \\
\hline & BS & 0.981 & 4.8 & 23.5 \\
\hline & $\mathrm{B}$ all & 0.991 & 3.5 & 10.5 \\
\hline \multirow{8}{*}{ NIR } & $\mathrm{AC}$ & 0.997 & 2.1 & 6.0 \\
\hline & AR & 0.995 & 2.4 & 7.4 \\
\hline & AS & 0.997 & 2.1 & 4.5 \\
\hline & $\mathrm{A}$ all & 0.995 & 2.5 & 6.3 \\
\hline & $\mathrm{BC}$ & 0.997 & 2.0 & 6.6 \\
\hline & $\mathrm{BR}$ & 0.997 & 1.9 & 5.8 \\
\hline & BS & 0.997 & 2.0 & 4.4 \\
\hline & $B$ all & 0.996 & 2.3 & 6.2 \\
\hline
\end{tabular}


Table 6. Cont.

\begin{tabular}{|c|c|c|c|c|}
\hline & Oil & $\mathbf{R}^{2}$ & RMSEPrange & Detection Limit [\%] \\
\hline \multirow{8}{*}{ Raman } & $\mathrm{AC}$ & 0.992 & 3.2 & 5.5 \\
\hline & AR & 0.993 & 3.0 & 9.0 \\
\hline & AS & 0.994 & 2.7 & 5.3 \\
\hline & A all & 0.984 & 4.6 & 11.2 \\
\hline & $\mathrm{BC}$ & 0.920 & 10.0 & 18.1 \\
\hline & $\mathrm{BR}$ & 0.986 & 4.1 & 11.6 \\
\hline & $\mathrm{BS}$ & 0.932 & 9.2 & 7.0 \\
\hline & B all & 0.938 & 8.9 & 12.0 \\
\hline \multirow{8}{*}{ Combined } & $\mathrm{AC}$ & 0.998 & 1.7 & 3.9 \\
\hline & AR & 0.996 & 2.3 & 7.4 \\
\hline & AS & 0.999 & 1.3 & 3.0 \\
\hline & A all & 0.997 & 2.1 & 5.8 \\
\hline & $\mathrm{BC}$ & 0.997 & 1.9 & 6.9 \\
\hline & $\mathrm{BR}$ & 0.998 & 1.6 & 6.8 \\
\hline & BS & 0.998 & 1.5 & 4.1 \\
\hline & $\mathrm{B}$ all & 0.997 & 1.8 & 4.3 \\
\hline
\end{tabular}

The RMSEP range values are more interesting; they were, with one exception, all below $5 \%$. For the regression of samples with chia oil A, the best results were obtained with NIR spectra. For $\mathrm{B}$, the best results were obtained with combined spectra. The highest error, corrected to the range of the considered samples (A, B, R, S, C), was RMSEP range $=10 \%$ for the evaluated Raman spectra alone, the lowest $1.3 \%$ for the combined evaluation of the spectra. The determination of the detection limit was not suitable for fluorescence spectra, as the smallest is $6.1 \%$. However, for NIR $(4.4 \%)$ and Raman, lower detection limits were obtained. It was found to be best with $3 \%$ of the spectra obtained with chia oil A adulterated with sunflower oil $S$ for the combined spectra evaluation. The best result for combined spectra evaluation for chia oil $\mathrm{B}$ was also obtained with $\mathrm{S}$ as adulteration oil with a detection limit of $4.1 \%$.

As can be seen in Table 7, for the Kenyan chia oils the RMSEP range was between $0.6 \%$ and $16.7 \%$. The detection limit varied according to the adulteration oil and it was better for the combined evaluations of the spectra. The measurements are regarded as unrepresentative because only a limited amount of sample was present. The detection limits were low (0.7/0.8 for Raman of $U$ and $Y)$, but the models had high RMSEP ranges, so the reliability of these results is questionable.

For this study, two Mexican chia oils and six Kenyan chia oils were evaluated. Therefore, the range within this study is higher than in the study presented by Rodríguez et al. [15]. The comparison is difficult as the methods and the study designs were different and it is not clear how they calculated their RMSEP. Here, six different classification methods were evaluated and a PLSR regression was performed to get an idea of the amount of adulteration and, furthermore the RMSEP ${ }_{\text {ranges }}$ were quite low in this study. The combination of all of the spectra was beneficial for the RMSEP range and the PLSR as the range is here between $1.3 \%$ and $2.3 \%$. This is better as presented by Rodríguez et al. [15] for the FT-IR analysis by SIMCA and OC-P-PLS. The comparison of the RMSEPs for the adulterated samples with A and B shows that, with one exception, the presented PLSR method is better than the other method, because the range of the RMSEP range was between $1.3 \%$ and $4.8 \%$. The classification sensitivity and specificity depended on the classification method which was sometimes lower, but mostly higher or at the same level. Oil B was easier to detect. However, it is difficult to compare the methods point by point, as the calculation of the RMSEP might be different as our RMSEP is standardized to the measurement range. For the Kenyan samples, the sample size was limited and the results might therefore be unrepresentative, but it proves the method working. 
Table 7. Results of the best PLSR predictions for the single chia oils $U, V, W, X, Y$ and $Z$ with single evaluations of the adulteration oil $\mathrm{S}$ separately for all methods and the combination of all methods.

\begin{tabular}{|c|c|c|c|c|}
\hline & Oil & $\mathbf{R}^{2}$ & RMSEPrange & Detection Limit [\%] \\
\hline \multirow{6}{*}{$\begin{array}{l}\text { Fluorescence with } \\
\text { Preprocessing }\end{array}$} & $\mathrm{U}$ & 0.999 & 1.5 & 3.8 \\
\hline & $\mathrm{V}$ & 0.995 & 3.0 & 5.3 \\
\hline & $\mathrm{W}$ & 0.999 & 1.5 & 3.1 \\
\hline & $x$ & 0.994 & 3.1 & 2.5 \\
\hline & $\mathrm{Y}$ & 0.993 & 3.5 & 4.7 \\
\hline & Z & 0.997 & 2.3 & 6.7 \\
\hline \multirow{6}{*}{$\begin{array}{l}\text { Fluorescence without } \\
\text { Preprocessing }\end{array}$} & $\mathrm{U}$ & 0.999 & 1.3 & 3.5 \\
\hline & $\mathrm{V}$ & 0.995 & 3.1 & 5.0 \\
\hline & $\mathrm{W}$ & 0.999 & 1.6 & 2.9 \\
\hline & $x$ & 0.994 & 3.1 & 2.6 \\
\hline & $\mathrm{Y}$ & 0.993 & 3.5 & 4.6 \\
\hline & $\mathrm{Z}$ & 0.997 & 2.1 & 7.8 \\
\hline \multirow{6}{*}{ NIR } & $\mathrm{U}$ & 1.000 & 0.6 & 1.6 \\
\hline & $\mathrm{V}$ & 0.995 & 3.1 & 11.3 \\
\hline & $\mathrm{W}$ & 0.998 & 1.9 & 5.6 \\
\hline & $x$ & 0.999 & 1.0 & 2.6 \\
\hline & $\mathrm{Y}$ & 0.999 & 1.3 & 2.2 \\
\hline & $\mathrm{Z}$ & 0.999 & 1.1 & 3.0 \\
\hline \multirow{6}{*}{ Raman } & $\mathrm{U}$ & 0.910 & 12.8 & 0.7 \\
\hline & $\mathrm{V}$ & 0.838 & 16.7 & 52.0 \\
\hline & $\mathrm{W}$ & 0.872 & 16.1 & 57.8 \\
\hline & $X$ & 0.889 & 13.2 & 2.2 \\
\hline & $\mathrm{Y}$ & 0.865 & 14.9 & 0.8 \\
\hline & Z & 0.838 & 16.7 & 52.0 \\
\hline \multirow{6}{*}{ Combined } & $\mathrm{U}$ & 1.000 & 0.6 & 1.6 \\
\hline & V & 0.996 & 2.7 & 8.0 \\
\hline & $\mathrm{W}$ & 0.999 & 1.4 & 2.7 \\
\hline & $x$ & 1.000 & 0.6 & 1.7 \\
\hline & Y & 0.999 & 1.3 & 3.3 \\
\hline & $\mathrm{Z}$ & 0.999 & 1.1 & 3.8 \\
\hline
\end{tabular}

\section{Conclusions}

The aim of the study was to answer following questions. Is it possible to detect chia oil adulteration by spectroscopic analysis of the oils? Is it possible to identify the adulteration oil? Is it possible to determine the amount of adulteration? The presented results suggest that it is possible to distinguish between different oils by fluorescence, NIR and Raman spectroscopy. It is possible to detect adulterations of chia oils and to distinguish between different adulterations. Here, adulterations of chia oils by rapeseed, sunflower and corn oil were identified with a median of $90 \%$ for the TPR. The training accuracies were over $90 \%$, the sensitivity and specificity of the classifications were over $90 \%$ too. B was easier to detect, so the precision was around $100 \%$ and the adulterated samples were identified with a precision of $97 \%$. All classification methods show good results, however SVM were the best. However, the classification by KNN is not suitable for this situation. The PLSR of A + B showed $\mathrm{R}^{2}$ over 0.95 for all models. The best RMSEP range of chia oil A was obtained by NIR spectra evaluation whereas it was best for oil B by combined evaluation of all spectra. The worst RMSEP range was obtained for Raman prediction of BC (10\%), the best for combined spectra predicting AS (1.3\%). For the Kenyan chia oils, the RMSEP range was between $0.6 \%$ and $16.7 \%$. However, only a small number of samples were measured. Detection limits varied according to the adulteration oil and were better for the combined evaluations of the spectra. It is also possible to identify the amount of adulteration, though less than $5 \%$ adulteration is difficult to identify. Further evaluations might lead to even better results, as there was not enough sample provided from the Kenyan oils. In conclusion, it is possible 
to identify adulterations from native samples by spectral analysis of the oils, depending on the adulteration oil. It is also better to combine all methods because a lower RMSEP range can be obtained. The best results might be obtained with a classification by SVM, to identify if an adulteration took place, with a following PLSR of all combined spectra to quantify it.

Author Contributions: Conceptualization, C.K., M.M. and V.Z.; methodology, V.Z.; software, O.P.D. and V.Z.; validation, M.M. and V.Z.; formal analysis, B.H.; investigation, C.K., M.M. and V.Z.; resources, B.H.; data curation, O.P.-D. and V.Z.; writing_-original draft preparation, V.Z. and M.M.; writing—-review and editing, V.Z. and M.M.; project administration, V.Z.; funding acquisition, M.M. and B.H. All authors have read and agreed to the published version of the manuscript.

Funding: This study was carried out at the Department of Process Analytics and Cereal Science at the Institute of Food Science and Biotechnology of the University of Hohenheim, supported by the DAAD German Academic Exchange Service under the Funding programme/-ID: Research Stays for University Academics and Scientists, 2019 (57440915).

Conflicts of Interest: The authors declare no conflict of interest.

\section{References}

1. Busilacchi, H.; Quiroga, M.; Bueno, M.; Di Sapio, O.; Flores, V.; Severin, C. Evaluación de Salvia hispanica L. Cultivada en el Sur de Santa fe (República Argentina). Cultiv. Trop. 2013, 34, 55-59. Available online: http:/ / www.redalyc.org/articulo.oa?id=19322854 6009 (accessed on 11 September 2019).

2. Ayerza, R.; Coates, W. Composition of chia (Salvia hispanica) grown in six tropical and subtropical ecosystems of South America. Trop. Sci. 2004, 44, 131-135. [CrossRef]

3. Ixtaina, V.Y.; Martinez, M.L.; Spotorno, V.; Mateo, C.M.; Maestri, D.M.; Diehl, B.W.; Nolasco, S.M.; Tomás, M.C. Characterization of chia seed oils obtained by pressing and solvent extraction. J. Food Compos. Anal. 2011, 24, 166-174. [CrossRef]

4. Wu, H.; Sung, A.; Burns-Whitmore, B.; Jo, E.; Wien, M. Effect of Chia Seed (Salvia hispanica, L) Supplementation on Body Composition, Weight, Post-prandial Glucose and Satiety. FASEB J. 2016, 30 (Suppl. 1), lb221. [CrossRef]

5. Gazem, R.A.A.; Puneeth, H.R.; Madhu, C.S.; Sharada, A.C. In Vitro Anticancer and Anti-Lipoxygenase Activities of Chia Seed Oil and Its Blends with Selected Vegetable Oils. Asian J. Pharm. Clin. Res. 2017, 10, 124. [CrossRef]

6. $\quad$ Albert, C.M.; Oh, K.; Whang, W.; Manson, J.E.; Chae, C.U.; Stampfer, M.J.; Willett, W.C.; Hu, F.B. Dietary $\alpha$-Linolenic Acid Intake and Risk of Sudden Cardiac Death and Coronary Heart Disease. Circulation 2005, 112, 3232-3238. [CrossRef] [PubMed]

7. Antruejo, A.; Azcona, J.O.; Garcia, P.T.; Gallinger, C.; Rosmini, M.; Ayerza, R.; Coates, W.; Perez, C.D. Omega-3 enriched egg production: The effect of $\alpha$-linolenic $\omega-3$ fatty acid sources on laying hen performance and yolk lipid content and fatty acid composition. Br. Poult. Sci. 2012, 52, 750-760. [CrossRef]

8. Dabrowski, G.; Konopka, I.; Czaplicki, S. Variation in oil quality and content of low molecular lipophilic compounds in chia seed oils. Int. J. Food Prop. 2018, 21, 2016-2029. [CrossRef]

9. Öztürk, B.; Ankan, A.; Özdemir, D. Olive Oil Adulteration with Sunflower and Corn Oil Using Molecular Fluorescence Spectroscopy. In Victor R. Preedy (Hg.): Olives and Olive Oil in Health and Disease Prevention, 1st ed.; Academic Press: Cambridge, MA, USA, 2010; pp. 451-461.

10. Kongbonga, Y.G.M.; Ghalila, H.; Onana, M.B.; Majdi, Y.; Ben Lakhdar, Z.; Mezlini, H.; Sevestre-Ghalila, S. Characterization of Vegetable Oils by Fluorescence Spectroscopy. Food Nutr. Sci. 2011, 2, 692-699. [CrossRef]

11. Zandomeneghi, M.; Carbonaro, A.L.; Caffarata, C. Fluorescence of Vegetable Oils: Olive Oils. J. Agric. Food Chem. 2005, 53, 759-766. [CrossRef]

12. Sikorska, E.; Górecki, T.; Khmelinskii, I.V.; Sikorski, M.; Kozioł, J. Classification of edible oils using synchronous scanning fluorescence spectroscopy. Food Chem. 2005, 89, 217-225. [CrossRef]

13. Osborne, B.G. Near-Infrared Spectroscopy in Food Analysis. In Robert A. Meyers (Hg.): Encyclopedia of Analytical Chemistry, Bd. 91; Wiley: Hoboken, NJ, USA, 2006; p. 49.

14. Rosa, L.N.; de Figueiredo, L.C.; Bonafe, E.; Coqueiro, A.; Visentainer, J.V.; Março, P.H.; Rutledge, D.N.; Valderrama, P. Multi-block data analysis using ComDim for the evaluation of complex samples: Characterization of edible oils. Anal. Chim. Acta 2017, 961, 42-48. [CrossRef] [PubMed]

15. Rodríguez, S.D.; Gagneten, M.; Farroni, A.E.; Percibaldi, N.M.; Buera, M.P. FT-IR and untargeted chemometric analysis for adulterant detection in chia and sesame oils. Food Control. 2019, 105, 78-85. [CrossRef]

16. de la Mata, P.; Dominguez-Vidal, A.; Bosque-Sendra, J.M.; Ruiz-Medina, A.; Rodríguez, L.C.; Ayora-Cañada, M.J. Olive oil assessment in edible oil blends by means of ATR-FTIR and chemometrics. Food Control. 2012, 23, 449-455. [CrossRef]

17. Maggio, R.M.; Cerretani, L.; Chiavaro, E.; Kaufman, T.S.; Bendini, A. A novel chemometric strategy for the estimation of extra virgin olive oil adulteration with edible oils. Food Control. 2010, 21, 890-895. [CrossRef]

18. Rohman, A.; Man, Y.C. Fourier transform infrared (FTIR) spectroscopy for analysis of extra virgin olive oil adulterated with palm oil. Food Res. Int. 2010, 43, 886-892. [CrossRef] 
19. Tay, A.; Singh, R.; Krishnan, S.; Gore, J. Authentication of Olive Oil Adulterated with Vegetable Oils Using Fourier Transform Infrared Spectroscopy. LWT 2002, 35, 99-103. [CrossRef]

20. Jović, O.; Smolić, T.; Primožič, I.; Hrenar, T. Spectroscopic and Chemometric Analysis of Binary and Ternary Edible Oil Mixtures: Qualitative and Quantitative Study. Anal. Chem. 2016, 88, 4516-4524. [CrossRef]

21. Fadzlillah, N.A.; Man, Y.C.; Rohman, A. FTIR Spectroscopy Combined with Chemometric for Analysis of Sesame Oil Adulterated with Corn Oil. Int. J. Food Prop. 2014, 17, 1275-1282. [CrossRef]

22. Ozulku, G.; Yildirim, R.M.; Toker, O.S.; Karasu, S.; Durak, M.Z. Rapid detection of adulteration of cold pressed sesame oil adultered with hazelnut, canola, and sunflower oils using ATR-FTIR spectroscopy combined with chemometric. Food Control. 2017, 82, 212-216. [CrossRef]

23. Rohman, A.; Man, Y.B.C. Palm oil analysis in adulterated sesame oil using chromatography and FTIR spectroscopy. Eur. J. Lipid Sci. Technol. 2011, 113, 522-527. [CrossRef]

24. Rohman, A.; Man, Y.B.C. Authentication of Extra Virgin Olive Oil from Sesame Oil Using FTIR Spectroscopy and Gas Chromatography. Int. J. Food Prop. 2012, 15, 1309-1318. [CrossRef]

25. Zhao, X.; Dong, D.; Zheng, W.; Jiao, L.; Lang, Y. Discrimination of Adulterated Sesame Oil Using Midinfrared Spectroscopy and Chemometrics. Food Anal. Methods 2015, 8, 2308-2314. [CrossRef]

26. Georgouli, K.; Del Rincon, J.M.; Koidis, A. Continuous statistical modelling for rapid detection of adulteration of extra virgin olive oil using mid infrared and Raman spectroscopic data. Food Chem. 2017, 217, 735-742. [CrossRef] [PubMed]

27. Zou, M.-Q.; Zhang, X.-F.; Qi, X.-H.; Ma, H.-L.; Dong, Y.; Liu, C.-W.; Guo, X.; Wang, H. Rapid Authentication of Olive Oil Adulteration by Raman Spectrometry. J. Agric. Food Chem. 2009, 57, 6001-6006. [CrossRef] [PubMed]

28. Nunes, C.A. Vibrational spectroscopy and chemometrics to assess authenticity, adulteration and intrinsic quality parameters of edible oils and fats. Food Res. Int. 2014, 60, 255-261. [CrossRef]

29. Márquez, C.; López, M.I.; Ruisánchez, I.; Callao, M. FT-Raman and NIR spectroscopy data fusion strategy for multivariate qualitative analysis of food fraud. Talanta 2016, 161, 80-86. [CrossRef]

30. Hu, O.; Chen, J.; Gao, P.; Li, G.; Du, S.; Fu, H.; Shi, Q.; Xu, L. Fusion of near-infrared and fluorescence spectroscopy for untargeted fraud detection of Chinese tea seed oil using chemometric methods. J. Sci. Food Agric. 2018, 99, 2285-2291. [CrossRef]

31. Li, B.; Wang, H.; Zhao, Q.; Ouyang, J.; Wu, Y. Rapid detection of authenticity and adulteration of walnut oil by FTIR and fluorescence spectroscopy: A comparative study. Food Chem. 2015, 181, 25-30. [CrossRef] [PubMed]

32. Cheong, A. Confusionmat Stats (Group, Grouphat). MATLAB Central File Exchange. 2021. Available online: https://www. mathworks.com/matlabcentral/fileexchange/46035-confusionmatstats-group-grouphat (accessed on 13 January 2021).

33. Wolfbeis, O.S.; Leiner, M. Charakterisierung von Speiselen mit Hilfe der Fluoreszenztopographie. Microchim. Acta 1984, 82, 221-233. [CrossRef]

34. Sikorska, E.; Gliszczyńska-Świgło, A.; Khmelinskii, I.; Sikorski, M. Synchronous Fluorescence Spectroscopy of Edible Vegetable Oils. Quantification of Tocopherols. J. Agric. Food Chem. 2005, 53, 6988-6994. [CrossRef] [PubMed]

35. Kyriakidis, N.B.; Skarkalis, P. Fluorescence Spectra Measurement of Olive Oil and Other Vegetable Oils. J. AOAC Int. 2000, 83, 1435-1439. [CrossRef] [PubMed]

36. Papoti, V.T.; Tsimidou, M.Z. Looking through the qualities of a fluorimetric assay for the total phenol content estimation in virgin olive oil, olive fruit or leaf polar extract. Food Chem. 2009, 112, 246-252. [CrossRef] 